\section{Burning Questions about Gas Hydrates}

by Barbara Maynard

M

ethane hydrates are nothing less than ice that burns. In an era of growing concern about energy prices and shortages, gas hydrates offer the potential of a vast new source of natural gas. These odd gas traps also are playing a role in the debate over global warming.

A Canadian fishing crew hauled in an unusual catch off the coast of Vancouver Island several years ago. Instead of fish, they netted what looked like a 450kilogram chunk of ice. Unlike ordinary ice, however, it began to hiss and steam. If a crew member had struck a match, the chunk would have burst into flame.

The ship had unwittingly discovered a large reserve of methane hydrate, a strange conglomeration of water ice and methane packed with hopes and fears in this era of growing concerns about energy supplies and energy's impact on the environment.

Methane hydrates, on one hand, could supply the world with a new source of clean energy that could last for decades. Methane $\left(\mathrm{CH}_{4}\right)$ is the main component of natural gas. Deep-ocean hydrate deposits also are a prime candidate for storing waste carbon dioxide from industrial smokestacks, rather than allowing it to enter the atmosphere. On the other hand, there are concerns that huge amounts of methane released from deep-sea deposits could shift global warming into high gear.

Regardless of their economic and environmental implications, gas hydrates are undoubtedly fascinating. Methane hydrates look like ice-until you put a match to them. Then they burn, as some researchers love to demonstrate. Methane hydrates form at relatively low temperatures and high pressures-such as those found at 500 meters or more under the ocean, for example. Under these conditions, water forms a cagelike structure that is stabilized through Van der Waals forces by the insertion of a molecule of gas into the cage. Various small gases can be the guest molecule, but the most common naturally occurring gas hydrates contain methane. Methane hydrates are found under the sea floor along outer continental margins and in permafrost regions-locations that provide

*Reprinted from Chemistry, winter 2006 issue, pages 27-33. Copyright 2006 Barbara Maynard. Contact <bmaynard@nasw.org> for reprint permission.

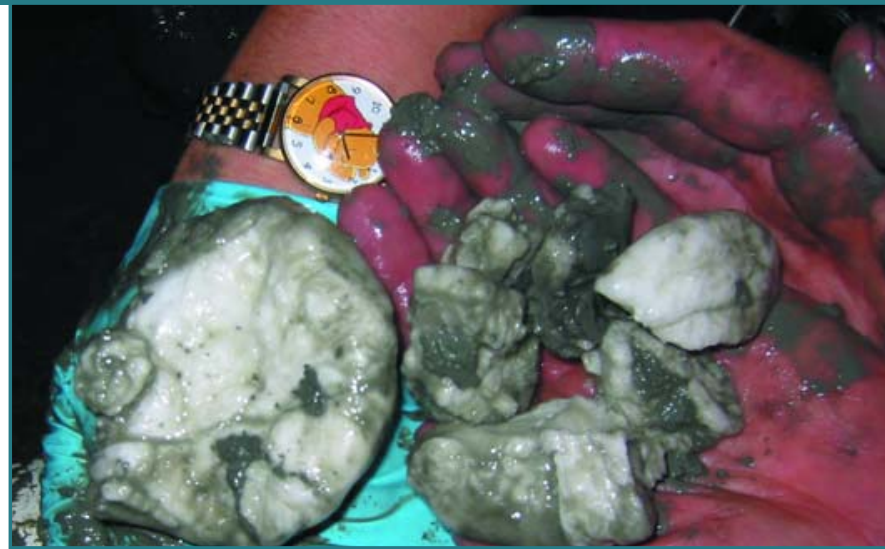

Chunks of gas hydrate recovered from a core taken in the Gulf of Mexico (USGS).

the high pressure, relatively low temperature, and large amounts of methane required for their formation. The margins are vast, relatively shallow areas of ocean floor along the continents.

The hydrate structure packs a lot of gas into a small volume: "The gas hydrate at 1 atmosphere of pressure will contain about 160 times the volume of methane as methane gas at that same pressure," said William Dillon, researcher emeritus with the U.S. Geological Survey (USGS). In contrast, liquefied natural gas has about 385 times the energy density of free gas.

\section{Energy Resource Potential}

Nobody knows exactly how much methane is frozen in hydrates, and the estimates range from about $1 \mathrm{Tt}$ ( $1 \mathrm{Tt}$ [terratonne] $=1012 \mathrm{t}$ ) of carbon in the form of methane to $22 \mathrm{Tt}$. Most experts put the figure at about $10 \mathrm{Tt}$. Earth's atmosphere contains about $0.7 \mathrm{Tt}$ of carbon. Put another way, the USGS estimates that the amount of natural gas in hydrate form is somewhere between $2.8 \times 10^{3}$ and $7.6 \times 10^{6} \mathrm{Tm}^{3}\left(1 \mathrm{Tm}^{3}=10^{12} \mathrm{~m}^{3}\right)$. That far exceeds remaining worldwide conventional natural gas resources, which are thought to total about $425 \mathrm{Tm}^{3}$.

In 2002, the United States used $0.76 \mathrm{Tm}^{3}$ of natural gas and global consumption totaled $2.6 \mathrm{Tm}^{3}$, according to the U.S. Energy Information Administration. Needless to say, hydrates have generated worldwide excitement about their potential as an energy source.

The U.S. Congress enacted the Methane Hydrate Research and Development Act of 2000, which charged the Department of Energy (DOE) with coordinating a national, collaborative effort toward the eventual exploitation of methane hydrates. Congress renewed the act in 2005 as part of the Energy Policy 


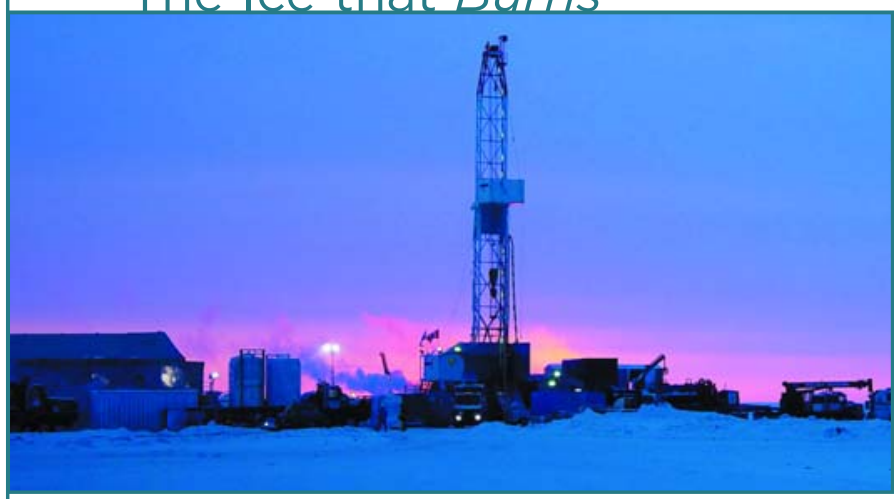

Drilling equipment at the Mallik site in the Canadian arctic was used for the first production test of gas hydrates (USGS).

Act, which also included a new provision for royalty relief. It includes subsidies for producing hydrates commercially by 2018. However, more work must be done in order to tap this resource.

International collaborations for hydrate research have formed among organizations and agencies from the United States, Japan, India, Germany, Canada, and other nations. Japan, for example, started a 16-year methane hydrate exploitation program in 2001. "Generally, everything is going well for the research program and we have learned much," said Takashi Uchida, a senior researcher with the Japan Petroleum Exploration Company. "Whether and when methane hydrate extraction will be economically viable should be considered in the next phase. Offshore production testing is planned early in Phase II, which will be the first offshore production test."

\section{Locating Hydrates}

Seismic data are the mainstay of current efforts to find potential hydrate fields. A pattern called a bottom-simulating reflector (BSR) in the seismic profile indicates the presence of hydrates-the dark band represents free gas trapped underneath an impermeable hydrate cap. The tool is not perfect, however. Hydrates have been found in the absence of a BSR.

A consortium of industry scientists sponsored by DOE has been developing a better method for detecting and characterizing gas hydrates in the Gulf of Mexico. During the spring of 2005, the team took to the sea to test their new technique. "The cruise is

one step in a process of trying to improve our ability to predict and quantify, for a number of reasons, where hydrates are located in the sediment," said Emrys Jones, research consultant with ChevronTexaco. The new method involves reanalyzing existing seismic data. Jones continued, "We would very much like to be able to do that with just conventional-type seismic information that is available, rather than have to spend a great deal of time and effort to locate the hydrates in another fashion."

The month-long research cruise aboard the semisubmersible vessel Uncle John collected ground-truth data by drilling cores and wells. "What we're trying to figure out now with this cruise is just how good a job we've done," Jones explained. "I would say that it's pretty clear that it's not perfect yet, but I don't know how far off from perfect it is. I think that we're going to end up with more modifications to our predictive techniques because we're not precisely getting what we predicted we'd get."

\section{Other Variables Affect Hydrate Stability}

While temperature and pressure curves are used to predict and describe regions of hydrate stability, other factors are also important. Carolyn Ruppel of the Georgia Institute of Technology argues that the spatial variability of salinity, temperature, and gas composition in the northern Gulf of Mexico deserve more

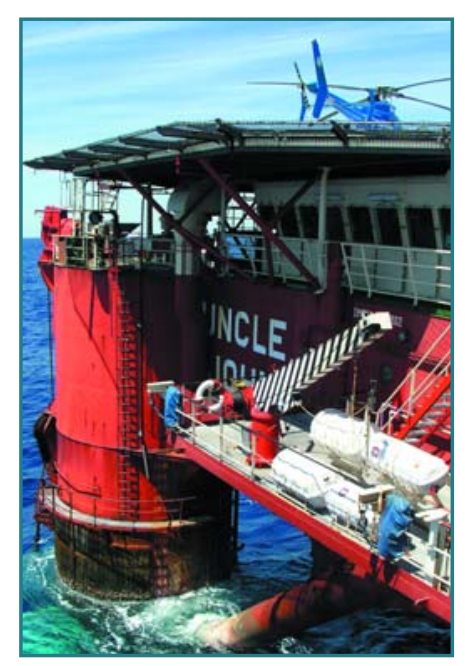

The semi-submersible vessel Uncle John was used on a Spring 2005 research cruise to study gas hydrates in the Gulf of Mexico (National Energy Technology Laboratory). attention in predicting hydrate reserves.

The Gulf of Mexico is rich with salt domes, old salt deposits buried deeply in sediments. "It's long been known that various salts, because of some ionic effects, inhibit the stability of gas hydrates," Ruppel said. "Once you start adding salt, you tend to make it more difficult to form gas hydrate or to keep it stable."

In addition to salt, heat might also play a bigger role in the northern Gulf of Mexico than previously considered. "Both of the sites we focused on in this paper [study] are mud volcanoes. People don't know a lot about mud volcanoes, but it appears that there's probably a lot of fluid coming from significant depths, and these are hot fluids," Ruppel said. "The other thing is 


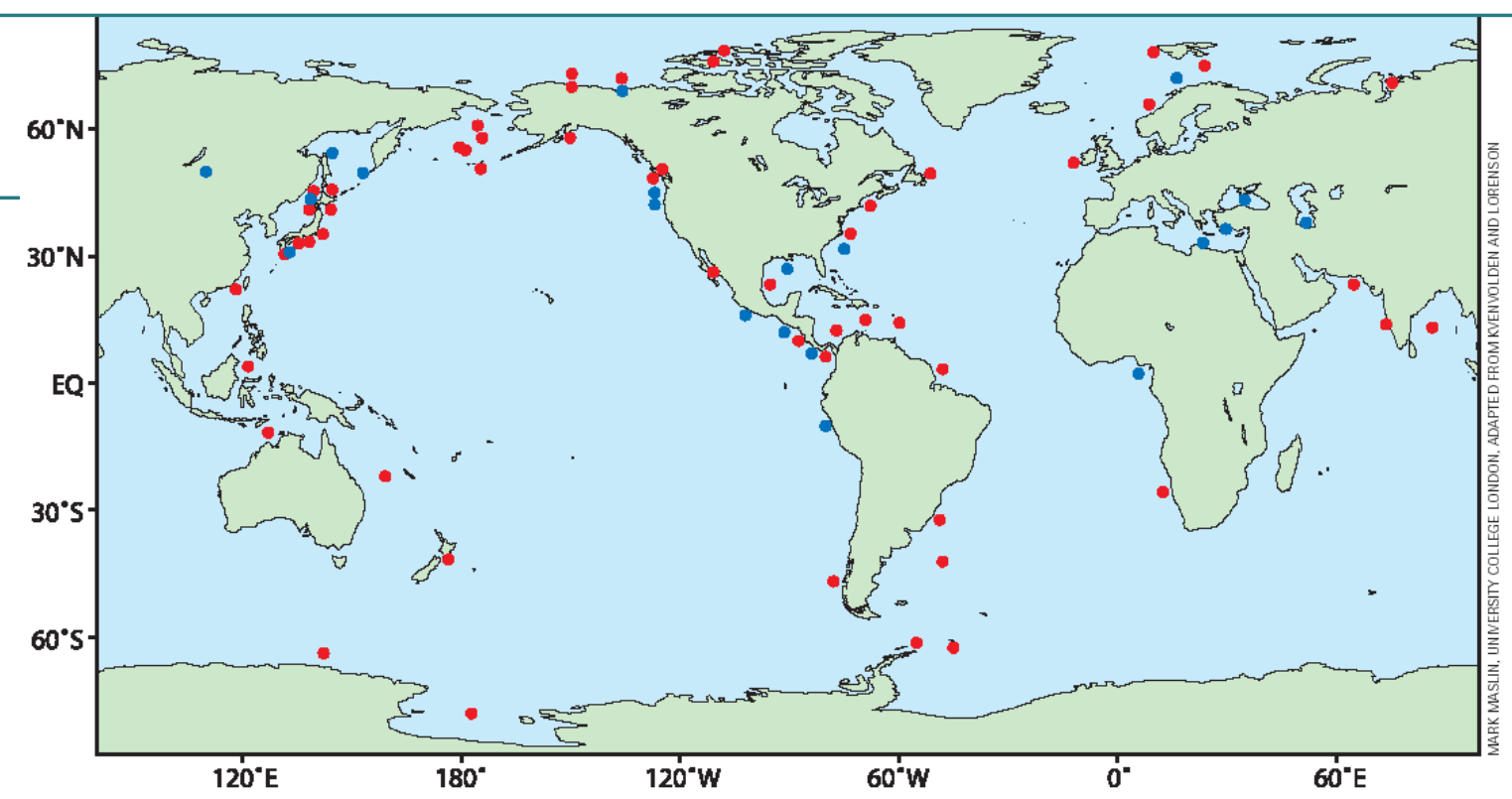

Red dots indicate locations where hydrate has been inferred from a BSR or other data. Blue dots indicate locations where gas hydrates have been recovered.

that the salt domes themselves actually contribute to raising temperatures in the sediments because salt has a very high thermal conductivity relative to the sediment. It seems that the northern Gulf has both thingsboth the temperature and salinity-working against it in terms of having a lot of gas hydrate in the sediments. It may be that the Gulf of Mexico is not the best target for looking for methane hydrates as a resource."

Ruppel is quick to point out the indirect nature of the study. "We didn't actually quantify the amount of hydrate," she said. "We were simply saying that if you look at where the stability field would be for hydrate, it's going to be a lot thinner than people have previously claimed and, therefore, there is likely to be less hydrate in these particular types of areas."

\section{How to Produce Hydrates}

While more work remains to be done to pin down exactly how much methane exists in hydrate form, there is little doubt that the final number will be large. Whether or not that methane will be economically viable to produce, however, remains to be seen.

Natural gas may have already been produced from hydrates in two permafrost areas. The Messoyakha gas field in Siberia was a conventional gas operation that tapped a reservoir trapped beneath hydrate. As gas was removed, starting in 1969, the site did not show the expected and typical decrease in production volume. Scientists have proposed that the years of continued production were maintained by the dissociation of hydrates, which broke down as the gas beneath them was extracted.

The first deliberate test of natural gas hydrate production took place in 2002 in the Mackenzie Delta of the Canadian Arctic. One production and two observation wells were drilled to almost 1200 meters deep in the Mallik gas field. One of the highest concentrations of natural gas hydrates known worldwide, the Mallik field is buried beneath permafrost over 600 meters thick. The project demonstrated the technical feasibility of producing natural gas from hydrates.

\section{A Hazardous History}

Hydrates first attracted attention in the 1930s, when natural gas pipelines started to clog in low temperatures, creating dangerous conditions and interrupting the flow of gas. Once researchers identified gas hydrates as the problem, they developed several strategies to deal with them. Insulating pipes from cold, heating them, or removing water from them can prevent hydrate formation, but these methods are not always feasible. Hydrate formation remains a major problem today. In the United States, for instance, the natural gas delivery system consists of 2.2-million miles of pipeline. If hydrate formation cuts off the flow, customers large and small that depend on natural gas face the consequences.

Adding either methanol or glycols inhibits hydrate formation, apparently by bonding to the hydroxyl group of the water molecules. However, this approach presents toxicity issues for the operator. Less toxic, low-dosage inhibitors are slowly gaining acceptance in the industry, according to Lynn Frostman of Baker Petrolite. The compounds incorporate themselves into the hydrate structure and prevent the growth of larger crystals. This allows hydrates to form, but prevents them from aggregating into large pieces that cause problems. 


\section{The Ice that Burns}

As conventional operations have pushed to drill deeper beneath the ocean floor in recent years, hydrates have presented new safety challenges. "When we are going after deeper hydrocarbons, we sometimes run across an area that has hydrates in it," Jones said. "The concern is how they will affect the sediments that we drill through, and how they will affect the sediments that we put productiontype equipment on."

Drilling through hydrates can release the pressure or raise the temperature as hot fluids are piped up from underneath the hydrate layer. Either effect can rapidly dissociate hydrates, leading to gas blowouts, highly pres-

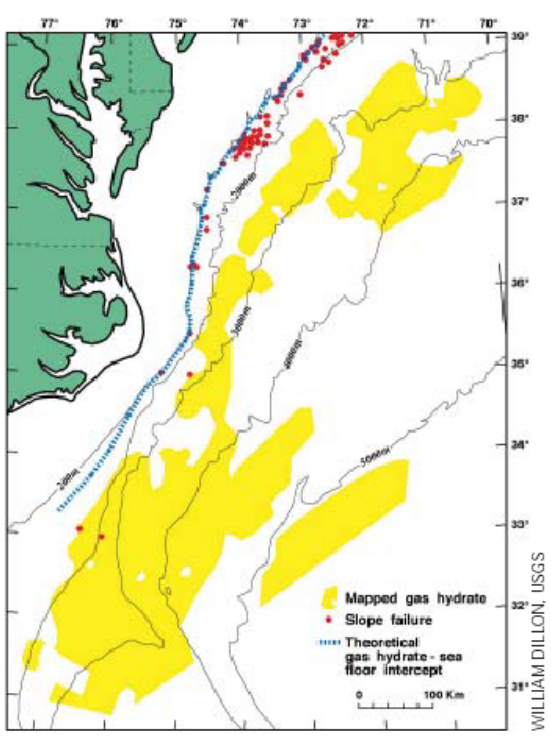

The theoretical upper limit of gas hydrate occurrence coincides with known seafloor failures.

\section{Hydrates and Global Warming}

Using natural gas for energy has environmental benefits. Burning pure methane produces carbon dioxide and water, and the high hydrogen-to-carbon ratio means less carbon dioxide is produced than from other fossil fuels. Therefore, natural gas is considered a relatively clean energy source. Hydrates, however, do have environmental drawbacks.

Because methane absorbs different wavelengths of energy than does carbon dioxide, it is 21 times more powerful as a greenhouse gas. Given hydrates' dependence on cold temperatures, this means not only that global warming can dissociate surized pockets of gas, or the collapse of sediments that support the drilling equipment.

"The hazards to industry infrastructure could potentially be substantial," Ruppel said. "For example, theoretically we're pumping hot fluids from a conventional oil reserve up through the hydrate stability zone. We could destabilize hydrates in the hydrate stability zone, and that part of the seafloor is what is holding up our platform."

Cores and drilling logs gathered on the 2005 Uncle John cruise will help engineers address these stability and safety issues. "We were trying to collect information on hydrate-bearing sediments that would tell us what their mechanical transport and acoustic-type properties are, for various reasons," Jones said. "Those things are used for the modeling of the well bore stability to know that when we are drilling a hole, it doesn't slough off or fall in on us."

While industry is learning more about how to model the behavior of hydrates, researchers are also refining means to prevent hydrate dissociation. "What you want to do when you're drilling is avoid melting the gas hydrate," Dillon said. "You can do that by insulating the pipe, by chilling the drilling fluid, by using inhibitors that make the gas hydrate more stable. There are drilling techniques that can be used to make drilling in gas hydrates safer." hydrates, but also that the subsequent release of methane can then exacerbate global warming, leading to a positive feedback loop-with negative consequences.

"The major recent finding from models of future climate change is that warming of the ocean $2-3^{\circ} \mathrm{C}$ will cause gas hydrate to break down in the ocean sediments and this will release methane into the ocean and atmosphere," said Mark Maslin of the Environmental Change Research Centre at University College London.

"What we learn from the past is that gas hydrates can be released either by rapid drops in sea level of tens of meters or temperature rises of $2-5^{\circ} \mathrm{C}$. We are entering a climate change period when ocean temperature outweighs sea level and thus gas hydrate release will occur. The only thing we can hope for is that it occurs slowly and this released methane oxidizes in the water column and thus stays in the ocean. If these releases are explosive, then the methane will be able to come straight into the atmosphere and accelerate global warming."

Maslin suggests that hydrates found below permafrost may be especially important in the coming decades for two reasons. First, high latitude temperatures are expected to rise in the next one hundred years by up to $8{ }^{\circ} \mathrm{C}$, and second, rising sea levels will flood areas of permafrost with water at $-1{ }^{\circ} \mathrm{C}$. 
"Compared with -20 to $-40{ }^{\circ} \mathrm{C}$ permafrost, this is a huge thermal shock, which will release any gas hydrate trapped there," Maslin said.

Methane hydrates have been implicated in past climate change and accompanying species extinctions. "I think they have played a major role in abrupt and massive climate changes like those at the $\mathrm{K} / \mathrm{T}$ boundary (Cretaceous-Tertiary boundary, 65 million years ago) and also the PETM (Paleocene-Eocene thermal maximum, 55 million years go)," Maslin wrote. The $\mathrm{K} / \mathrm{T}$ boundary marks the transition from the dominance of dinosaurs to that of mammals, and the PETM corresponds to the rise of terrestrial animals, including primates, and the fall of many deep ocean species.

Some scientists have thought that methane hydrates could mediate climate change if a rise in sea level caused by melting ice caps increased pressure enough to enlarge the hydrate stability zone. However, recent calculations predict that this will not happen with the current global warming pattern. "The sea level increase predicted for the next 100 years is too small (20-80 centimeters) to have any stabilizing effect on the gas hydrate reserves," Maslin wrote.

Dissociation of

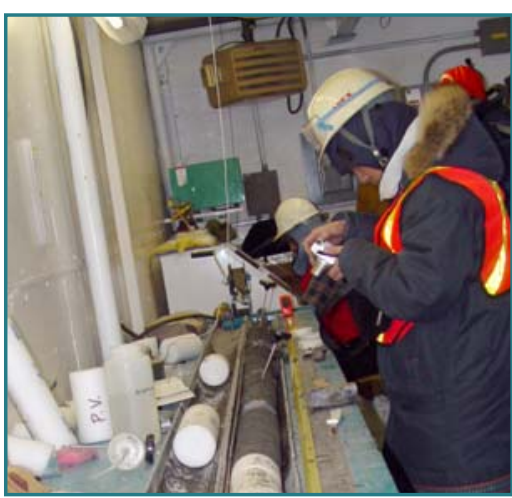

Cores recovered from the Mallik drilling operation were quickly preserved in liquid nitrogen to preserve them for later analysis of gas content, porosity, thermal conductivity, and other characteristics (USGS). hydrates can also lead to undersea landslides as the solid "ice" that had cemented the sediment together disintegrates into liquid water and gas. Dillon made the connection between hydrates and landslides in work he did with Jim Booth of the USGS. "I had been mapping gas hydrates on the east coast of the United States," Dillon said. "We looked at the

map of the gas hydrates and superimposed that on a map of the landslides off the east coast of the United States." The tops of the major landslides all occurred near the gas hydrate limit.

Hydrate-triggered landslides, in conjunction with the consequent release of more gas from beneath the hydrate, can in turn cause tsunamis. "We would expect these gas hydrate-caused failures to produce tsunamis in areas that normally do not experience them, for example, the North Atlantic," Maslin wrote. "The Norwegian Storegga slide of 8000 years ago caused a 15-meter high tsunami (about the same height as the 2004 Boxing Day tsunami in southeast Asia)."

\section{New Applications: Sequestering Carbon Dioxide and Storing Methane}

Ram Sivaraman, principal scientist at the Gas Technology Institute (GTI), believes hydrates can be a source of energy while simultaneously reducing global warming. He is developing a strategy to sequester carbon dioxide and produce methane in the same process.

"When I did some calculations, the heat of formation for hydrates of carbon dioxide is close enough to the heat of dissociation for methane hydrates," he said. Therefore, it is thermodynamically possible to replace methane with carbon dioxide in deep-sea hydrate sediments. Sivaraman has successfully tested his idea in a high-pressure chamber at GTI. Under conditions that mimic those in the Gulf of Mexico, he injected carbon dioxide into methane hydrate-containing sediment. "The calculations indicated that the hydrate didn't dissociate, but still we are getting methane," he said. "There is only one way it can happen-if carbon dioxide is going in and displacing methane in the sediments." He said this process has two benefits: "No matter how much methane you get, still carbon dioxide has been sequestered."

Sivaraman is also working on a project to store natural gas in hydrate form. Promoters-the opposite of the chemical inhibitors used to prevent hydrate formation in pipelines-facilitate the formation of methane hydrates at room temperature, provided there is sufficient pressure. Development of this approach would enable storage of large reserves of natural gas efficiently, which he suggests will be a cost-effective way for large cities to weather periods of high demand and short supply of natural gas.

Barbara Maynard <bmaynard@nasw.org>, Ph.D., is a freelance science writer in Alaska, where she is getting firsthand exposure to both changing climate and growing excitement over the energy potential of methane hydrates. 